\title{
El fotoperiodismo dentro del escenario migratorio en las costas marítimas de la Unión Europea
}

Lacette Maria Lehnen Cojocaru

Universidad de Granada, España

Francisco Jiménez Bautista

Universidad de Granada, España

Antonio M. Lozano Martín

Universidad de Granada, España 



\title{
El fotoperiodismo dentro del escenario migratorio en las costas marítimas de la Unión Europea
}

\section{Photojournalism within the migratory scenario of the maritime coasts of the European Union}

\author{
Lacette Maria Lehnen Cojocaru \\ Universidad de Granada, España \\ lacette@correo.ugr.es
}

Francisco Jiménez Bautista

Universidad de Granada, España

fjbautis@ugr.es

Antonio M. Lozano Martín

Universidad de Granada, España

lozanoma@ugr.es

Fecha de recepción: 24 de octubre de 2018

Fecha de aceptación: 20 de enero de 2020

\begin{abstract}
Resumen
Este artículo analiza un conjunto de escenas fotográficas en las costas marítimas de la Unión Europea (UE), divulgadas por fotógrafos presentes en los lugares a los que llegan los inmigrantes. Intentamos responder a la pregunta: ¿Cuál es el lugar del sujeto en el mundo? a través del análisis de las imágenes seleccionadas que reproducen este drama humanitario. Desde una metodología hermenéutica, intentamos dar respuesta a la retórica de la exclusión que dibuja, metafóricamente, dos mundos separados; los inmigrantes frente a los residentes europeos y pone de manifiesto el (no)lugar del inmigrante en el discurso de las políticas migratorias de la UE. El resultado es la reproducción del imaginario colectivo que alimenta el racismo y las xenofobias donde la invisibilidad del inmigrante tiene su construcción social. Concluimos que los cambios positivos, pueden estar representados en las manos solidarias de los que salvan vidas en el Mediterráneo que desvelan una mirada (imagen simbólica) de que solo existe un mundo, y en él, viene el derecho a la una vida digna para todos.
\end{abstract}

Palabras clave: Discurso iconográfico; Fotoperiodismo; Inmigración; Mediterráneo; Unión Europea. 


\begin{abstract}
This article analyses a set of photographs of the maritime coasts of the European Union (EU), released by photographers located in places where immigrants arrive on precarious ships, fleeing poverty and the wars that afflict them. The study tries to answer the question "What is the place of the subject in the world?" through the analysis of the selected images that reproduce a humanitarian drama. The results indicate the following discursive arguments: the rhetoric of exclusion draws, metaphorically, two separate worlds, immigrants versus European residents, and highlights the (non)place of the immigrant in the discourse of EU migration policies; a reproduction of the collective imaginary that feeds racism and xenophobia, where the invisibility of the immigrant is a social construct; the positive changes for humanity, which can be represented in the hands of solidarity of those who save lives in the Mediterranean, revealing a symbolic image: There is only one world, and with it, the right to a dignified life for all.
\end{abstract}

Keywords: Iconographic Speech; Photojournalism; Immigration; Mediterranean; European Union

\title{
1. INTRODUCCIÓN
}

Los últimos siglos han sido los de mayor avance tecnológico y científico de toda la historia de la humanidad. Un avance tecnológico que expande la supremacía de las máquinas y posiciona al hombre como dependiente de sus propias invenciones. El capitalismo avanzado (Sassen, 2015) inaugura la era del consumo compulsivo. Los nuevos conocimientos contienen la paradoja de una dicotomía difundida históricamente por las fuerzas de la dinámica del poder; una parte de la sociedad garantiza el poder del conocimiento, mientras que otro segmento de la humanidad está excluido de múltiples formas (Castells, 2009). Los discursos sociales (políticos, económicos y culturales), además de mediáticos, institucionalizan las conductas de repudio hacia el otro, reconstruyendo narrativas que reavivan los racismos y la xenofobia de todos los géneros (Jiménez, 1997, 2006; Van Dijk, 2006; Cea D’Ancona y Valles, 2015; Castilla-Vazquez, 2017; Pérez, 2018; Chakour y Fernández, 2018).

Es un contexto ambiguo, pues esta misma sociedad, marcada por la globalización, redefine el concepto de frontera y dibuja la poderosa fisionomía económica mundial con un aumento de la riqueza de los países desarrollados de un $66 \%$ en los últimos 20 años, mientras que el resto de los países continúan empobrecidos. Los últimos datos registran que la mayoría de las personas que viven con menos del equivalente a un dólar al día se encuentran en Asia Meridional, seguido de la pobreza extrema de más de la mitad de la población del África subsahariana (Banco Mundial, 2017; Santana, 2017)

Un pasado de colonización y larga esclavitud ha dejado como legado un aprendizaje a los gobernantes de cómo apropiarse de las riquezas, pues después de 
la independencia, muchos de estos mismos países han terminado por convertirse en sistemas de gobierno dictatorial que continúan usurpando sus propias riquezas y atentando contra la dignidad humana de sus habitantes. Este absolutismo genera desigualdad y pobreza, que se añaden a las rebeliones entre grupos étnicos y religiosos, y fomentan las crisis humanitarias y las migraciones forzadas en busca de la sobrevivencia (Cavero, 2012; Oroza y Puente, 2017). Según informaciones de la Organización de las Naciones Unidas (ONU, 2017) «los conflictos armados que están proliferando, los problemas derivados del cambio climático, la inseguridad alimentaria y la escasez de agua provocan efectos negativos en las fronteras» (cfr.: Martínez y Acosta, 2017).

La pobreza y exclusión social que se asocian a los países colonizados y la dispersión demográfica producida por las guerras hacen de la migración un fenómeno de crisis sin precedentes, considerado el mayor éxodo poblacional desde la II Guerra Mundial (Vargas, 2015; Bauman, 2016; Oroza y Puente, 2017). Un fenómeno que interrumpe el proyecto de vida de millones de personas que son expulsadas de su propio hogar. La creciente movilidad de personas, principalmente en el contexto de la Unión Europea, se detiene debido a las fuertes barreras del centro del capitalismo avanzado y las duras políticas migratorias de deportación. Asistimos, pues, a un viejo-nuevo ciclo en que el discurso dominante parece marcar el rumbo de la segregación y de la expulsión de los grupos humanos, como el gran malestar de la actualidad, desencadenante del fenómeno del capitalismo salvaje, de las guerras, de la pobreza y de las políticas migratorias excluyentes.

A través de los registros estadísticos se puede comprobar la gran tragedia humanitaria del siglo XXI tras el número creciente de muertes en el Mediterráneo. La Organización Internacional para las Migraciones (IOM) informa que 2016 fue un año en el que más de 5.000 personas murieron en la travesía en el Mar Mediterráneo. Por otro lado, el Alto Comisionado de las Naciones Unidas para los Refugiados (ACNUR) informa de que la inseguridad, la crisis económica, los abusos y las explotaciones en Libia, han forzado a los refugiados e inmigrantes a huir hacia Europa. La crisis de Sudán del Sur también amplió la población refugiada: «con un aumento del $64 \%$ en la segunda mitad de 2016 , esta población pasó de 854.100 personas a más de 1,4 millones, la mayoría de ellas menores de edad». En total, según las estadísticas de dicho año, más de la mitad de los refugiados del mundo (aproximadamente un 55\%) procedía de los siguientes países: «Siria con 5,5 millones de refugiados, Afganistán con 2,5 millones y Sudán del Sur, uno de los más pobres y menos desarrollados del mundo, con 1,4 millones de desplazamientos». También hubo «552.000 refugiados retornados durante el año, así como aproximadamente 189.300 reasentados y 23.000 naturalizados» (ACNUR, 2016, pp. 3-7).

Son acontecimientos relatados al instante a través del mass media, que ostentan un gran poder sobre la opinión pública internacional en lo relativo a las 
catástrofes que enfrentan una parte de la humanidad, además de sobre los ataques terroristas del Estado Islámico, que en nombre del fundamentalismo religioso extrapolan su barbarie e instituyen la desesperación humana, «agudizando el éxodo» (Arango, 2017, p. 35). La separación de unos, frente a los otros se enmascara a través de la dualidad social que se repite continuamente en la historia de la humanidad (Van Dick, 2006; Santana, 2017).

En la actualidad, son las nuevas tecnologías las que ofrecen nuevas formas de divulgación de las catástrofes humanitarias, de las diferencias humanas y del fenómeno migratorio sin precedentes. Los periodistas están allí en cada llegada de barcos y son los que registran las imágenes conmovedoras de los inmigrantes que consiguen llegar vivos, a pesar del número progresivo de muertes en una travesía por el Mediterráneo llena de riesgos. La cobertura mediática de las noticias de asilo, de los refugiados, de la trata de personas e inmigrantes escrita y fotografiada, viene amparada por la ética deontológica contemplada en la Carta de Roma (Italia, 2008), a pesar de no ser un documento oficial, y algunas «instituciones defensoras de los Derechos Humanos emiten informes y recomendaciones destinadas a los medios de comunicación para el tratamiento informativo de la crisis de los refugiados» (Peña, 2017, p. 9).

La divulgación de las fotografías virtuales hace posible la eternización de los hechos producidos en las costas marítimas de la UE e identifica quiénes son los protagonistas de las imágenes. Sin embargo, el número de investigaciones derivadas de las fotografías de la inmigración en las costas marítimas de la UE es ínfimo. La divulgación periodística de imágenes asociadas al texto son las más comunes, quedando registradas en bancos de imágenes cuyo acceso está restringido por una cuestión de derechos de autor, coexistiendo el uso para estudiantes y profesionales del área de Comunicación en el dominio Open Access. Para el área de las Ciencias Humanas y Sociales aún queda el compromiso de desarrollar más estudios sobre los significados de las imágenes, que apuntan a una crisis fundamentada en una colonización imperialista cuyas consecuencias se vinculan a la realidad actual de la crisis política y humanitaria; son como «cicatrices del marcado ADN europeo en las urbes de África» (EL PAÍS, 11-02-2018).

Finalmente, las fotografías tomadas reproducen el caos y revelan el drama humano en las costas marítimas de la UE como un trágico fenómeno social, considerado como una auténtica violación de los derechos humanos. La repercusión mediática del nefasto número de muertes por ahogamiento y el impacto de la inmigración han movilizado a los dirigentes políticos de la UE y la discusión del tema migratorio ha sido recurrente en el Parlamento Europeo. Por el contrario, se asocia, en cada una de las categorías analizadas, un elemento más fotografiado cuyo lenguaje fotográfico permite reavivar hitos que no se puede pueden olvidar. 


\subsection{Objeto de estudio}

A pesar de que la deportación de los inmigrantes en situación irregular de cualquier país del mundo es una práctica de la jurisprudencia afín y contenida en el Derecho Internacional de Extranjería, la UE aprobó con detalles su propia normativa en el año de 2008, identificada como la Directiva de Retorno, que presenta las prerrogativas del proceso de «expulsión de los inmigrantes en situación irregular de terceros países» $(2008 / 115 / \mathrm{CE})$. A mediados de 2010, se desencadenó la crisis de los países de lengua árabe, con la movilización organizada a través del uso de redes sociales como Facebook, Twitter y YouTube, para sensibilizar a la población y a la comunidad internacional acerca de la represión política y censura que estaban sufriendo en distintas formas. Este proceso se denominó la «Primavera Árabe» (Joffé, 2011).

Los efectos en la UE fueron inmediatos con la «Primavera Árabe» provocando, por primera vez, la reformulación del Acuerdo de Schengen, aumentando los controles interiores para frenar la entrada de inmigrantes «ilegales» huidos de estos conflictos. Además de reforzar la vigilancia por mar, tierra y en los aeropuertos, la Agencia Europea para la gestión en las fronteras exteriores de los Estados miembros de la Unión Europea (FRONTEX), desarrolló nuevas estrategias de contención de los inmigrantes. La Comisión Europea presentó el 13 de mayo de 2015 la Agenda Europea de Migración (2015, p. 240 final), en la que «se esbozan medidas inmediatas para responder a la situación de crisis en el Mediterráneo» y debilitar a los traficantes de personas reforzando una política eficaz de retorno (Agencia Europea de Migraciones, 2015, 285 final, p. 3).

El acuerdo de la UE y Turquía de 2016 agiliza la deportación de refugiados desde las islas de Grecia, produciendo una violación a los Derechos Humanos. Se constata, a través de las normativas actualizadas y reinventadas para gestionar la crisis humanitaria, que la UE tiene como foco perfeccionar las medidas de expulsión de los inmigrantes «ilegales» como medida de protección a la fortaleza europea. Con la inversión de miles de millones de euros en los controles de entrada de personas en su territorio, la UE ratifica, en la Cumbre de Malta de 3 de febrero de 2017, un Plan de Acción renovado en materia de retorno y un conjunto de recomendaciones a los Estados miembros para lograr que los procedimientos de retorno sean más eficaces.

Para la realización del presente estudio se ha optado por el uso de fotografías como objeto de análisis del contexto migratorio en las costas marítimas de la UE. Esta decisión está fundamentada en la frase de Eddie Adams, que afirma que «la fotografía es el arma más poderosa del mundo»; con ella es posible hacer la guerra o parar la guerra. Eddie Adams fue el autor de la imagen icónica que cumple 50 años divulgada en El Periódico (31-01-2018) por Josep Saurí con el titular «La foto que cambió el rumbo de la guerra de Vietnam cumple 50 años». Fue la imagen 
de una ejecución a sangre fría en plena calle en Saigón que se convirtió en icono de la campaña antibelicista en EEUU, en 1972. Otras fotografías emblemáticas que registraron el caos humanitario y que corroboran que la fotografía es un instrumento de divulgación y de análisis de los fenómenos sociales, fueron, por ejemplo, las tomadas durante los horrores del Holocausto (1942-1945). Son miles de fotografías que recrean los escenarios y actualizan en nuestros ojos el pánico y desesperación humana frente a una de las mayores tragedias humanitarias decurrentes de la II Guerra Mundial. El ataque a las torres gemelas de World Trade Center y el efecto mediático a través de las imágenes han dibujado una nueva escena mundial que incluyó intervenciones militares de los EE.UU., en Afganistán y en Irak, con interminables guerras que provocaron la caída de gobiernos dictatoriales en el Continente Africano y Medio Oriente, y fue el marco de las migraciones desesperadas hacia otros países, principalmente a través del Mediterráneo. En este contexto, la fotografía del cuerpo de un niño sirio de tres años muerto en las costas turcas en el naufragio de un barco dirigido a Grecia en septiembre de 2015, tomada por Nilufer Demir de la agencia Dogan News Agency se convirtió en la imagen símbolo del drama de los refugiados en las costas marítimas de la UE.

Este recorrido distingue el objeto de estudio con base en la frase que argumenta que la fotografía puede cambiar el rumbo de la historia y que una «imagen puede valer más que mil palabras». Específicamente en el caso de las migraciones en las costas marítimas europeas, las imágenes que circulan en las redes sociales y en los grandes periódicos son una señal de denuncia de lo que sucede en la Unión Europea, solidarizándose con el drama humanitario y sensibilizando a la comunidad internacional para concretar una resolución que no suponga una violación de la Declaración de los Derechos Humanos,

Los sujetos, en el contexto de las fotografías analizadas son los personajes del discurso de la inmigración desesperada hacia las costas europeas, siendo que el estudio pretende desvelar las escenas protagonizadas que ellos -como inmigranteson personas con rostro y nombre que no pueden ser invisibles a los ojos del mundo. En otras palabras: «fotografiar es conferir importancia» (Sontag, 2006, p. 109).

El artículo tiene como objetivo general, analizar el discurso silenciado de los sujetos protagonistas de las imágenes que representan las escenas de los contextos migratorios actuales y el drama humanitario en la travesía del Mediterráneo hacia la UE. Los hechos eternizados a través de la fotografía pueden provocar la emoción de lo ocurrido, el día y el momento que pueden ser recontados y revividos en la imagen.

\section{METODOLOGÍA}

En el mundo contemporáneo la imagen pasó a ser registrada por la fotografía, que perpetúa el momento en sí mismo y consigue dar vida a los elementos fotografiados a través de la interpretación discursiva. Barthes (1980), uno de los precursores del 
Análisis del Discurso, certificó que en el discurso de la imagen hay una «significación» y que los interpretantes analizan su «significado». Los presupuestos básicos del análisis de la fotográfica suponen tener mensajes connotativos y denotativos. Unos describen lo que representa la imagen y los otros recuperan el contexto de la ideología valiéndose de los conocimientos sociales (económicos, políticos y culturales), históricos y psicológicos, lo que convierte la imagen fotografiada en un discurso lingüístico que evoca la realidad en contexto.

De igual manera, Umberto Eco (1988), en sus estudios sobre la semiología fotográfica, afirmó que la teoría de la imagen supone una teoría del significado y de la interpretación, que se fundamenta en el sistema cultural del contexto que la representa. Es necesario conocer el entorno económico, político y cultural, cuya intertextualidad presupone un universo cultural conocido por aquel que se propone hacer el análisis del discurso. Además, exige del intérprete la capacidad de descifrar la intención de aquel que ha registrado la imagen y la experiencia, en la fase de interpretación, con el apoyo de los factores de orden social, histórico e ideológico (Kristeva, 1978).

La decisión de optar por fotografías como objeto de estudio de las migraciones actuales en la UE se ha fundamentado en la realidad caótica que enfrentan los inmigrantes, destituidos del poder de voz y del derecho al libre tránsito entre fronteras. De la misma forma se ha fundamentado en los estudios precursores del uso de la fotografía en el ámbito de las migraciones, principalmente, abordados junto con los acontecimientos políticos, económicos y climáticos de impacto materializado en tantos éxodos humanos, que se puede traducir como migraciones forzadas por la escasez y por las guerras. Las dos guerras mundiales nos dejan un acervo de fotografías y de historias donde cada una de las familias emigradas, recuerdan sus antepasados que abandonaron la patria, y son los inmigrantes de hoy hacia Europa fotografiados al momento que conviven con la barbarie institucionalizada.

No obstante, se entiende que la incorporación de la fotografía en los estudios etnográficos y de la sociología visual, específicamente con el tema de las migraciones, solo contribuyen en la contextualización de realidades vividas por las personas. Es lo que Enric Mira Pastor logra cuando circunscribe tres proyectos documentales sobre la inmigración: A los invisibles (2004) de Consuelo Bautista; Europa, tan cerca tan lejos (2004) y Distrito (2006) de Salvi Vivancos. Enric Mira nos señala que «son trabajos documentales que ponen de manifiesto la voluntad de objetivar la compleja verdad de la inmigración y, ante todo, el compromiso ético por comprenderla a través de sus personales lenguajes fotográficos» (Mira, 2008, p. 104). En otro estudio, Franquet, Real y Beriain (2015, pp. 286-287) centra en el análisis de las noticias y fotografías de «la representación de los inmigrantes en cuatro diarios españoles», la aplicación del código deontológico para la praxis ética, pues «las informaciones inciden notablemente en las representaciones sociales del imaginario colectivo». 
Por otro lado, la fotografía, al ser una imagen instantánea de la realidad, es la mejor herramienta del registro de las incoherencias sociales, cuando el discurso de la palabra encubre el pasado de la opresión y se disfraza en elocuentes retóricas disponibles en el lenguaje verbal y en la demagogia política del poder (Martínez y Jiménez, 2015; Gómez et al., 2017).

El método que se ha utilizado en este estudio consta de dos fases, una primera fase en la que se realiza un análisis de documentos iconográficos divulgados por la prensa localizada en las costas del Mediterráneo, y una segunda parte de acercamiento etnográfico a la realidad de nuestro objeto de estudio, que es la representación de la inmigración «ilegal» en el contexto de las costas marítimas de la UE. A través de la selección de ocho imágenes desde la página Web 2.0 donde cuatro corresponden al corpus del análisis. Las otras cuatro fotografías que constan en el artículo son las que registran la importancia de la imagen como herramienta de estudios ya que hace un registro visual de los hechos marcados de la historia de la de la humanidad y de la (des)humanización en la que se encuentra la Unión Europea. De otro modo, son fotografías que movilizaron la percepción subjetiva de estos escritos y que tiene que ser asimismo una fotografía de la realidad social en la que estamos inmersos.

El proceso de análisis y presentación de los resultados siguen las propuestas de los autores como Kristeva (1978); Barthes, (1980); Eco, (1988); Sontag (2006); Van Dijk, 2006; y, Martínez y Jiménez (2015), conforme sigue:

a) Contexto: Delimitación del lugar donde fue tomada la fotografía; Fecha; Hecho(s); Pie de página; Autor y protagonista(s).

b) Análisis connotativo: Descripción de la fotografía según los datos objetivos $\mathrm{y}$ visibles.

c) Análisis Denotativo o Semántico: Elucidar los significados e interpretarlos con base en el contexto histórico y político de la ideología vigente, lo que convierte la imagen fotografiada en un discurso lingüístico que evoca la realidad en contexto.

Los presupuestos teóricos con base en la definición de las categorías del análisis del discurso de las imágenes se fundamentan en la fenomenología de Merleau-Ponty que conceptualiza la existencia humana en términos de cuerpo-vivido, un término que el autor utiliza para expresar conceptos sobre el cuerpo mientras esté vivo e implicado en el sentido de estar en el mundo. El Merleau-Ponty señala que «en la medida que tengo manos, pies, un cuerpo, sostengo a mi alrededor intenciones que no son dependientes de mis decisiones y que afectan lo que me rodea de una manera que yo no elijo» (Merleau-Ponty, (1971[1952]).

Son reflexiones previas de los autores del presente artículo, constituyéndose determinantes para delimitar las cuatro categorías en el proceso de Análisis del 
Discurso de las imágenes: 1. El poder de las manos; 2. Los inmigrantes (no) son invisibles; 3. Una pisada para la esperanza; 4. Los cuerpos tienen un nombre.

\section{DATOS Y DISGUSIONES}

El marco teórico y metodológico se va a explicitar con cuatro ejemplos que nos ayuden a comprender la situación en la que se encuentran las personas que llegan a las costas de la Unión Europea durante el periodo comprendido entre 2000 a 2016 reveladores del caos en el que están inmersos las personas inmigrantes. En cada una de las categorías construidas, se presenta una fotografía de análisis y otra imagen de finalización con similar contenido semántico, algunas en contextos y tiempos diferentes de la historia.

\section{1. ¡El Poder de las Manos!}

a) Contexto

Mar Mediterráneo, frente a la costa de Libia. Fecha: octubre del 2016. Pie de página: Un miembro de la ONG Proactiva Open Arms rescata a un inmigrante. Autor: Aris Messinis/ AFP.

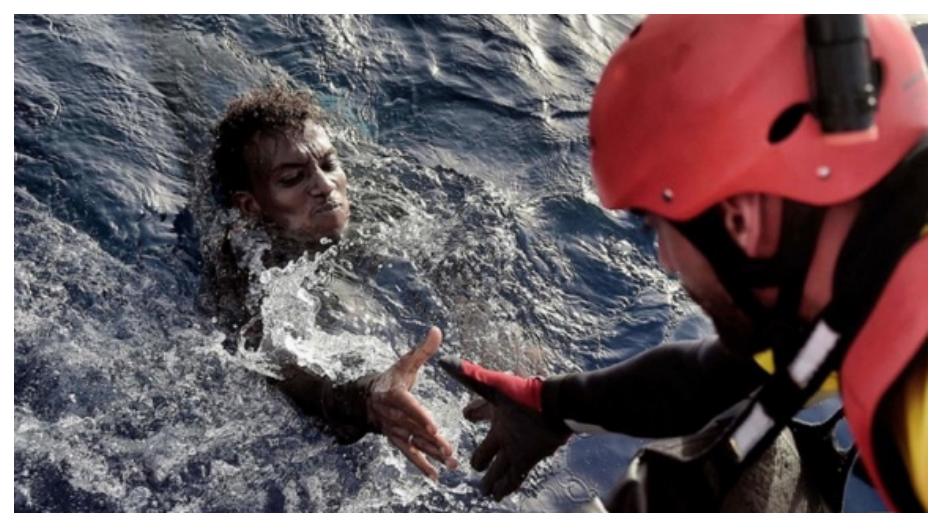

Imagen 1. ¡Dáme la mano!

Fuente: www.elperiodico.com/es/noticias/internacional/proactiva-open-arms-opta-premio-desobiencia- civil-boston-6005997

\section{b) Análisis Connotativo}

Se trata de una fotografía tomada en un mar que se muestra agitado. El inmigrante, solo con la cabeza fuera del agua, parece estar ahogándose y tiene su mano extendida a la persona de la ONG que lo intenta rescatar. Las ropas del rescatador evidencian una preparación previa y una protección apropiada para la 
entrada en el mar, con colores muy visibles (rojo, negro y amarillo), mientras que la persona en situación de un posible naufragio está vestida con una camisa de color marrón y lleva un anillo en uno de los dedos de la mano que pide ayuda.

\section{c) Análisis Denotativo}

Un momento solidario fotografiado puede construir una figura de héroe social. Este es el caso de la Imagen 1, que ha recibido el Premio a la Desobediencia, (Instituto de Tecnología de Massachussets (MIT), «sea un ejemplo de desobediencia en beneficio de la sociedad», organizado por MIT en 2017. La fotografía no solo reproduce una acción humanitaria con el salvamiento de un inmigrante en alta mar, sino que además refleja una conducta delictiva hacia la política europea, infringiendo la Directiva 2002/90/CE, «destinada a definir la ayuda a la entrada, a la circulación y a la estancia irregulares», cuyo artículo $1^{\circ}$ letra a) impone sanciones para «cualquier persona que ayude a otra que no sea nacional a entrar en el territorio de un Estado miembro de la UE». A pesar de que la normativa no prevé sanciones para los casos en que «el objetivo de esta conducta sea prestar ayuda humanitaria a la persona de que se trate», las acciones de las ONG destinadas a salvar vidas en el mar están siendo interpretadas como una violación a la legislación sobre la entrada o tránsito de extranjeros.

Es inadmisible que en siglo XXI, además, de las guerras, la pobreza, la marginación y la exclusión social de todo tipo, una ley impide el salvamiento de personas que están a punto de ahogarse en el mar. Sin embargo, la memoria histórica hace recordar cuáles fueron los objetivos de la construcción de una comunidad europea, entre los cuales destaca el evitar toda y cualquier discriminación humana que pudiera repetir el holocausto de la II Guerra Mundial. Ahora, en nombre del poder, son los propios parlamentarios, representantes de los países que componen el bloque europeo, los que alzan el poder de sus manos para votar con un simple «sí» las normativas que definen cuál es el (no)lugar (Augé, 1993) de los que intentan llegar en la UE.

Es la realidad del siglo, que el inmigrante de la foto representa a miles de personas desesperadas que enfrentan los riesgos del mar, paradójicamente, para intentar salvarse de las guerras y de la pobreza de sus países, y el que extiende la mano muestra el poder de la solidaridad. La Coordinadora Internacional de Global Coalition on Migration afirma que los inmigrantes buscan salvarse a través de la clandestinidad por la ausencia de canales regulares y seguros adecuados, que es precisamente lo que empuja a los migrantes a emprender viajes peligrosos y los aboca a la irregularidad (Maulik, 2017).

Si el poder de las manos políticas ejerce el dominio de la exclusión, el poder de las manos solidarias está cambiando el contexto de la crisis humanitaria, incluso con una simple mano y un único disparo de su cámara, el fotógrafo eterniza una 
realidad. Es lo que afirma Medina (2016), «nuestra petición de socorro para el desconocido es curiosamente selectiva». Las manos que salvan son la prueba de la sensibilidad humana que, en medio del individualismo y la xenofobia, están empeñadas en salvar vidas en el Mediterráneo que ahora es el cementerio de los sueños. Son también el poder de las manos que demolieron las piedras, junto los significados del muro de Berlín. La fuerza de un pueblo ha promovido el fin de la guerra fría y el derrumbe del comunismo en 1989. Una de las expectativas con la derribada del muro era tener un mundo con las fronteras abiertas. Sin embargo, aún se construyen muros reales, simbólicos y burocráticos para impedir la entrada de los inmigrantes en muchas partes del mundo.

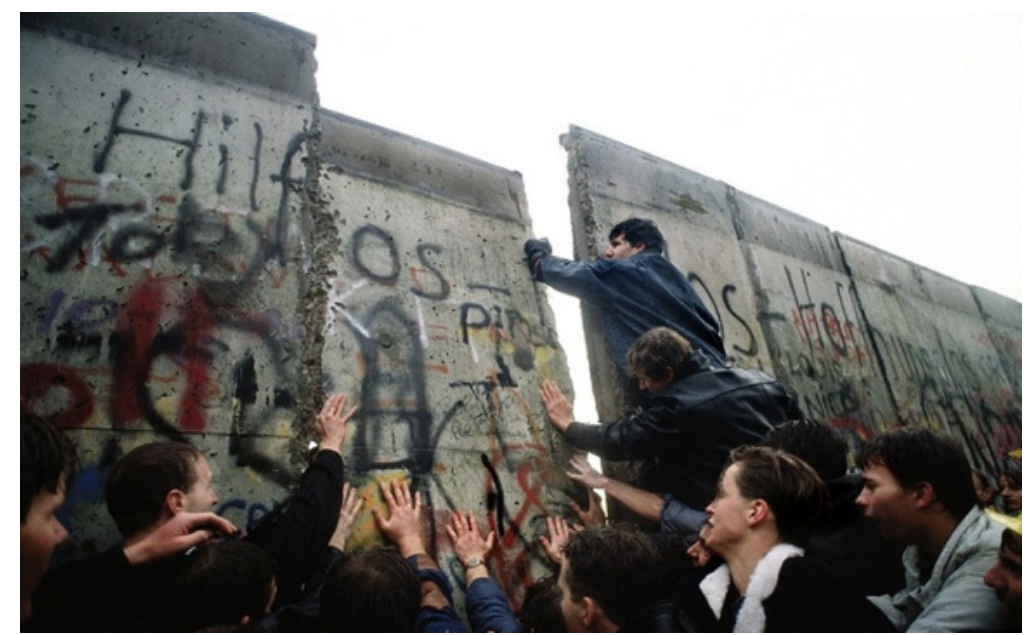

Imagen 2. ¡Démonos las manos!

Fuente: Queda del muro de Berlín, 1989 / EFE

3.2. ¡Los inmigrantes (no) son invisibles!

a) Contexto

Arena de una playa en Lanzarote en España (después de llegar una patera). Fecha: 2009. Pie de página: Un inmigrante subsahariano sin papeles llega a una playa española; Fuente: Periodismo Digital.

b) Análisis Connotativo

Es una fotografía de una persona cuya semblanza ocupa casi la mitad del cuadro. Él camina arrodillado en las arenas de una supuesta playa. Se trata de un 
hombre negro vestido con un abrigo marrón y pantalón negro que no lleva zapatos. A pesar de que sus ropas son de una estación más fría, en el mismo escenario, a la derecha del hombre, se pueden observar tres personas con ropa de playa, dando a entender que puede ser verano. De estos protagonistas, un hombre casi tumbado en la arena viste un bañador corto y las otras dos personas parecen ser mujeres, una de ellas con un bañador de una pieza y la otra con un short y blusa de verano. Parece que están charlando entre sí, sin dar indicios de que puedan estarse percatando de lo que ocurre a la izquierda de la posición en la que se encuentran.

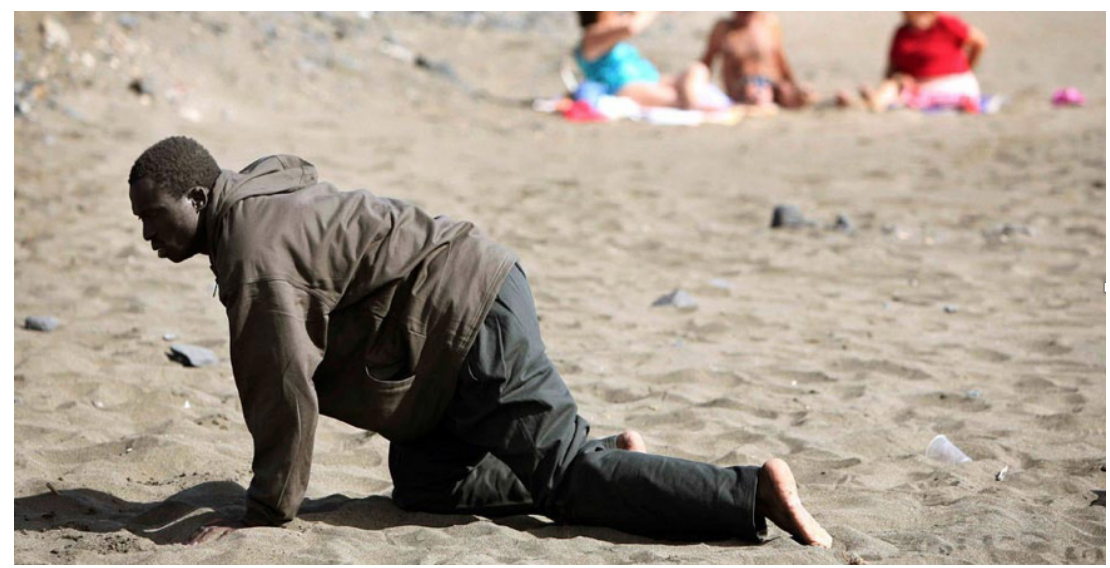

Imagen 3. ¡(No) soy invisible!

Fuente:http://www.periodistadigital.com/inmigrantes/vida-cotidiana/2010/01/01/2009-acaba-patera-cayuco-menor-llegada-papeles-inmigrantes-origen-visado-anos.shtml

\section{c) Análisis Denotativo}

Es la Imagen 3 de un joven que llega a la arena agotado. Tanto que solo consigue caminar a gatas. En el pie aparece la leyenda indica que se trata de «Un inmigrante sin papeles que llega a una playa española». El responsable del pie de página, al escribir tal afirmación, reproduce lo que es público y conocido: Solo llegan inmigrantes de esta manera, en pateras precarias, si no tienen papeles. Resalta que es una inmigración «ilegal» pero no subraya que la gran mayoría de los inmigrantes que llegan a las costas españolas son del África subsahariana, que provienen del caos social, económico y ecológico marcado por el pasado de colonización que se funde con la escasez actual.

En cuanto a las personas que se encuentran disfrutando de la playa, supuestamente en vacaciones, no parecen preocuparse por la persona que llega casi sin fuerzas al país que, en su imaginario, es el paraíso. El descaso de las dos mujeres y el hombre quizás esté reflejando un hecho cotidiano de las costas marítimas de la UE, más específicamente de España, que ha pasado a formar parte de la rutina; la llegada 
continua de barcos-patera con muchas personas del África Subsahariana. Las noticias obtenidas de un único periódico revelan, aún en la portada, una forma discriminatoria de referirse a llegada de inmigrantes: "Oleadas de pateras en las costas andaluzas» (El Mundo, 28-05-2017). Este titular revela que el uso de eufemismos en el lenguaje como «oleada» se traduce en el comportamiento de los lectores, aumentando la xenofobia y la aversión al otro, acostumbrándose a no verlos, pues las personas empobrecidas son invisibles a los ciudadanos del capitalismo implacable.

Sin embargo, la debilidad del hombre que llega, sin duda con sed y hambre, junto con la insensibilidad de las personas, se puede asociar al propio pasado de la nación europea. En otro capítulo de la historia fueron también los europeos, huyendo de la pobreza y de las guerras, quienes invocaron la generosidad más allá de los mares. Al igual que el itinerario de las aceleradas emigraciones ha cambiado, es imposible concebir que un pueblo olvide su pasado. Quizás sea lo que señala Lacan (1970, p. 46), «mientras haya la anulación del tiempo no habrá deseo de saber», lo que ocurre es como si fuera la primera vez, donde los escenarios similares se dibujan como si fueran nuevos.

Es lo que logramos con la fotografía que traduce las ideas de supresión de lo que se repite, para negar la responsabilidad de los cambios sociales. Es la imagen de una pareja en la playa, que hace caso omiso a un inmigrante muerto cerca de ellos. Re-divulgada por el propio fotógrafo, Javier Bauluz (2015) en el Vigésimo Encuentro Internacional de Foto y Periodismo en Gijón bajo el título Quince años después, Europa sigue bajo la sombrilla. En la fecha actual, aún persiste la cuestión: ¿Continuamos como espectadores de la tragedia humana?

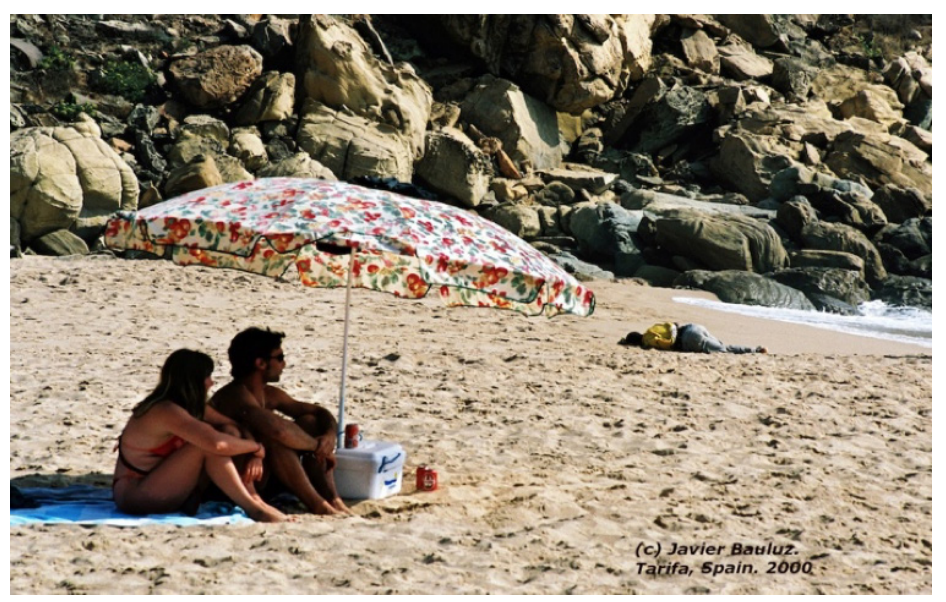

Imagen $4: ;(\mathrm{No})$ te miramos!

Fuente: Tarifa, Cádiz (España) en el año 2000 (Bauluz) 
3.3. ¡Una pisada para la esperanza!

a) Contexto

Refugiados en la carretera. Fecha: 22.06.2016; Pie de página: Refugiados y Esclavitudes; Autor: libertario, Contagio Radio @Contagioradio1; Fuente: César Torres Del Río.

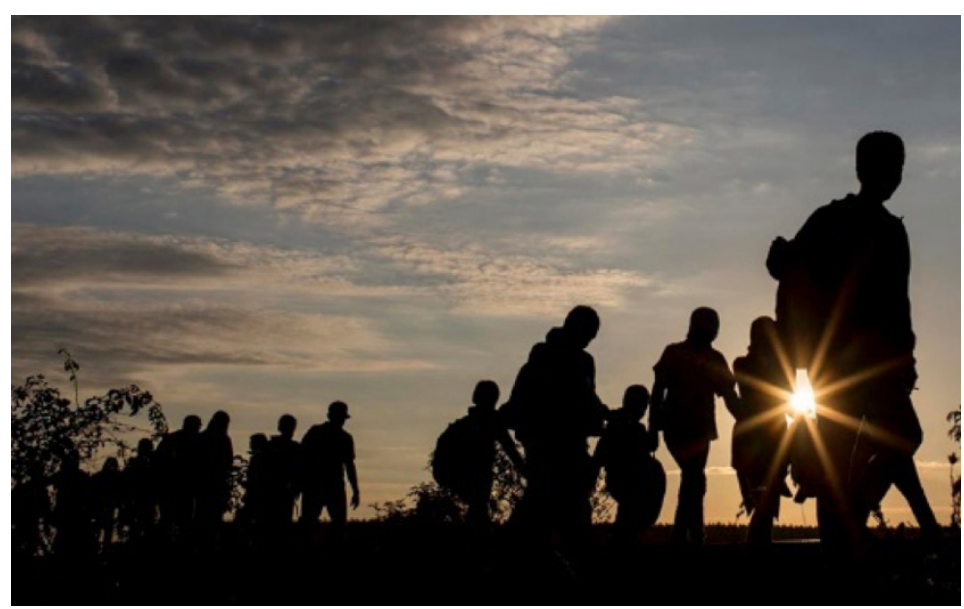

Imagen 5. ¡El camino para la vida!

Fuente: http://www.contagioradio.com/refugiados-y-esclavitudes-articulo-25589/

\section{b) Análisis Connotativo}

En la fotografía se observan varias personas caminando en un atardecer, en el que el Sol se pone creando un espectro de luz entre las manos de uno de los inmigrantes. Andan en fila, sugiriendo que los pequeños están sostenidos por la mano del adulto que lleva una mochila en la espalda. El tono, el contraluz y la vestimenta ligera de las personas transmiten la sensación de una época calurosa. Los protagonistas de la Imagen 5 parecen caminar en silencio y con cierta solemnidad.

\section{c) Análisis Denotativo}

Se podrían seleccionar muchas imágenes para representar a los grupos de personas inmigrantes que han conseguido pisar tierra después de sobrevivir una peligrosa travesía a través del Mediterráneo, dejando atrás la pesadilla de la guerra y del hambre. Sin embargo, se ha optado por una imagen que refleja, por su propia 
oscuridad, la realidad de lo que continúa siendo una tragedia en el Mediterráneo. Y junto a la oscuridad, la representación simbólica, a través de pisadas incansables, de la esperanza de las personas y de la incertidumbre de un futuro en el que sufrirán la ambivalencia de las políticas migratorias de la UE, que los criminalizará por llegar sin documentos y que los clasificará, bien como inmigrantes ilegales por causas económicas, o bien como inmigrantes ilegales que necesitan protección y pueden solicitar el asilo. Esa esperanza inicial de salvación, representada por la primera pisada en tierra firme, se fundirá rápidamente con la certeza de que los zapatos pisan un espacio volátil, en el que el discurso político les asegura que la libertad está mucho más allá y que la caminata es larga.

Una de las pruebas del Holocausto fueron los zapatos de las víctimas que fueron encontrados y que están expuestos en el museo de Auschwitz; los son los pares de zapatos que componen el monumento creado en recuerdo a las víctimas de la II Guerra Mundial que fueron arrojadas a las aguas del río Danubio en Budapest, cuyas pisadas marcan el lugar donde fueron ejecutadas. Pero al igual que estas, las fotografías de miles de personas atravesando países que cierran sus puertas de entrada con muros y cercas alambradas, son también prueba de esta tragedia humanitaria del siglo XXI, inscrita en el mayor éxodo humano desde la II Guerra Mundial. Personas cuyos zapatos continúan pisando con la esperanza de encontrar algún lugar en el que puedan retomar sus vidas y recuperar los derechos que han sido violados en sus países de origen, y que son tratadas como persona non grata en la Unión Europea.

Son muchos los obstáculos a los que deben enfrentarse las personas inmigrantes en su lucha por encontrar un futuro: la valla entre la frontera turca y griega, cerca de Erdine; la valla fronteriza entre Turquía y Bulgaria en la localidad de Kraynovo; la alambrada con cuchillas en la frontera entre Hungría y Serbia; la triple valla de seis metros de altura de Ceuta y Melilla, entre España y Marruecos (Ananou y Jiménez, 2016), o la cerca con alambre de púas en Calais entre Francia e Inglaterra (Vargas, 2015). Todas estas vallas dibujan el peor escenario del caos de la humanidad en el momento actual y son el reflejo de la deshumanización de quienes quieren poner fin, de forma cruel, a la situación caótica de la migración. Una migración debida, por otro lado, a las guerras y el hambre existente en países herederos de la violencia política y la desenfrenada apropiación de riquezas que los propios países europeos llevaron a cabo en el pasado, a la ganancia del poder hegemónico de los dictadores, y a los conflictos étnicos y religiosos, dibujan las imágenes del éxodo humano en busca de sobrevivencia y la paradoja de la (in)civilización (Jiménez, 2009). Es lo que exprime el monumento basado en la historia de la II Guerra Mundial que representa la incoherencia humana, la xenofobia y el racismo exacerbado. Muestra el contenido inverso de la pisada para la esperanza, pues los protagonistas dieran un último paso, y esto fue para la muerte. 


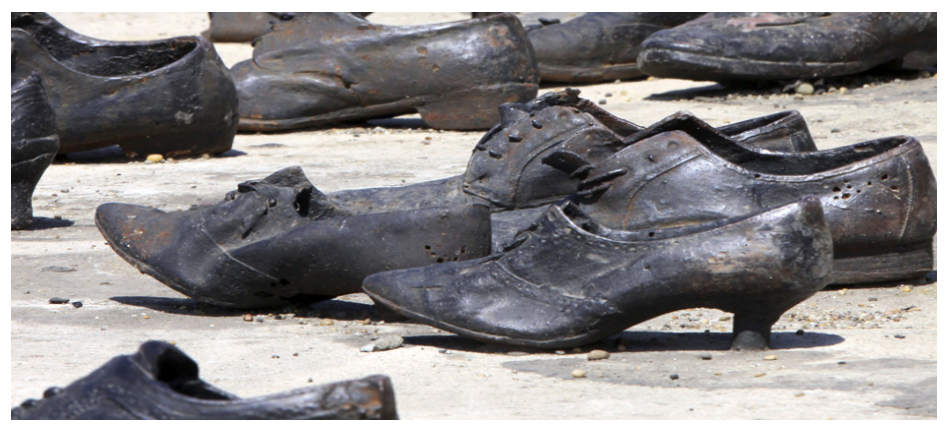

Imagen 6: ¡Un paso para la muerte!

Fuente: Obra de Gyula Pauer y Can Togay (2005), Budapest

\section{4. ¡Los Cuerpos Tienen un Nombre!}

a) Contexto

Hangar en el aeropuerto de Lampedusa; Fecha: 09.10.2013; Pie de página: Ataúdes con víctimas del naufragio de Lampedusa; Autor: Corby (La Repubblica it).

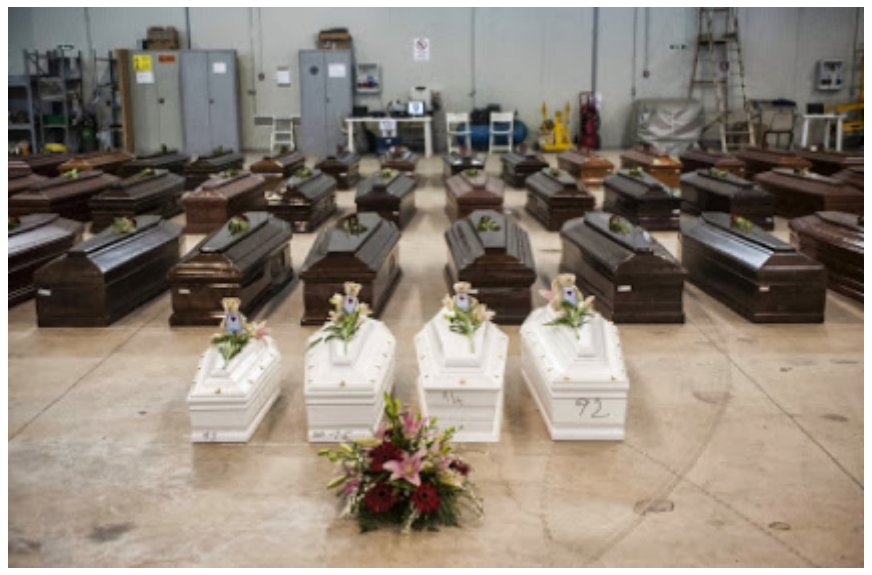

Imagen 7. Ahogados en Lampeduza

Fuente: https://www.hotelpalestina.com/

b) Análisis Connotativo

Se trata de una fotografía de los ataúdes de las víctimas de la tragedia del naufragio en la isla de Lampedusa (Italia). Están dispuestos en tres filas largas, por el número de fallecidos. Parece que están numerados, por el número 92 que se observa en el cajón blanco en primer plano. Las urnas de madera de color marrón son de los adultos hombres y mujeres muertos, y los cuatro ataúdes pequeños de color blanco 
son de los niños que murieron en el naufragio. Hay una flor roja depositada encima de cada uno de los ataúdes de los adultos y otra blanca en los de los niños, junto a un osito de peluche. Delante de todos los ataúdes hay un centro mayor de flores.

En la Imagen 7 se pueden observar objetos como escaleras, mesas, sillas y armarios, que pertenezcan al local original donde se encuentran los féretros, a pesar de no encajar con el contexto de la fotografía con los ataúdes. Se puede imaginar lo que tuvieran de modificar el ambiente para recibir los efectos de las duras políticas migratorias de la UE, que se materializó a través de tantas muertes, la tragedia humana que ocurre en el Mediterráneo.

\section{c) Análisis Denotativo}

Se puede pensar que no son solo los inmigrantes los que están en los ataúdes, sino que simbólicamente se encuentran todos los que permanecieron en sus países de origen. En muchos casos fueron las familias -quizás nunca sepan de la muerte de sus hijos- las que se movilizaron a lo largo de los años tratando de juntar unos pocos ahorros para el pago del viaje de uno de sus miembros, que rembolsan a los traficantes que se aprovechan de la situación de vulnerabilidad de los migrantes, prometiendo la seguridad de la travesía y haciendo de esto un negocio lucrativo. El que migra es muchas veces «el elegido» para vivir en un mundo nuevo, pero también asume la carga y la responsabilidad tanto de enviar dinero, como de intentar romper el ciclo repetitivo de la pobreza.

Sin embargo, es un viaje con barcos precarios cuya llegada es incierta; en el camino mucho son tragados por el mar. La situación caótica vivida por el ahogamiento de más de 300 personas en 2013 no fue un hecho nuevo, considerando que la única vía de entrada de los sin papeles es la peligrosa ruta del Mediterráneo. Las severas políticas migratorias y las operaciones comandadas por la UE tienen la misión de salvar vidas (Frontex) y desmantelar las mafias a través de la Operación Sophia, pero la mayoría de los salvamentos en los puntos de llegada de las costas marítimas europeas son efectuados por ONG. Es ahí donde se observa la primera incongruencia de las políticas migratorias de la UE. La prioridad debería ser salvar vidas, pero no existe ningún compromiso al respecto. La protección llega solo cuando los inmigrantes acaban de salir del mar; después son llevados hacia los centros de internamiento (CIE), a la espera de la decisión judicial para la deportación a sus países de origen, conforme las cláusulas de la Directiva de Retorno (2008/115/CE), y ratificada en el Plan de Acción de 2015 (2015, 510 final).

Otro reflejo de la incongruencia ocurrida en el siniestro de Lampedusa, asociado a divulgación mediática internacional en contra las medidas severas de la UE, fue la actitud «benevolente» asumida por el gobierno italiano que tomó la decisión de enterrar a las víctimas con honores de Estado, y lo más cínico fue el hecho de que para los supervivientes del naufragio, los tramites de deportación fueron agilizados. 
Es un comportamiento discursivo pregonado aun por Freud (1976, [1919]) que decía que «nadie es inmune a los engaños». La disimulación política ha desvelado la proposición de que, «entrelineas», la muerte de los «ilegales» conviene más que sus vidas, dado que la extrema pobreza no ofrece nada al capitalismo salvaje que ostenta y sustenta la hegemonía imperialista.

La prueba más contundente de los disfraces que utiliza la máquina del poder fue la movilización del Parlamento Europeo para realizar los cambios y refuerzos de las normativas migratorias europeas. A grandes rasgos, el objetivo fue evitar un nuevo desastre similar al ocurrido en la isla italiana, pero en realidad la meta era frenar la migración «ilegal» hasta la UE y el éxodo de los refugiados provenientes, principalmente, de la Guerra de Siria. Entre los documentos más actuales se encuentran el Acuerdo de la UE con Turquía (2016) y la Agenda Europea de Migración (2015) hasta el año 2020 que, entre innumerables perspectivas de acción, describe el fortalecimiento de la expulsión de los inmigrantes y de los refugiados cuando es denegada su petición de asilo, además de consolidar el riguroso control de fronteras y el encarcelamiento de los traficantes de personas.

El juego de poder de las diferentes normativas tiene un precio impagable, pues no resuelve la cuestión de la invisibilidad que se consolida en el anonimato de los ataúdes; aquellos que huyen de sus hogares para impedir la muerte y que justo la encuentran en el rescate de la vida. Los ahogamientos no solo representan el final de los sueños cerrados en una urna. Ahí se disipan las memorias, las historias de vida y su (no) lugar como sujeto en el mundo, donde lo único que permanece es la cuestión: ¿Cuáles son sus nombres? ¿Se repite en Europa, en el momento actual, lo que la comunidad europea intenta olvidar? Si los incontables ataúdes del genocidio nazi han dejado miles de personas sin nombre, aún las tragedias actuales provocadas por las migraciones «indeseables» los identifican por números de muertos, pues sus nombres y sus historias fueron tragados por el mar.

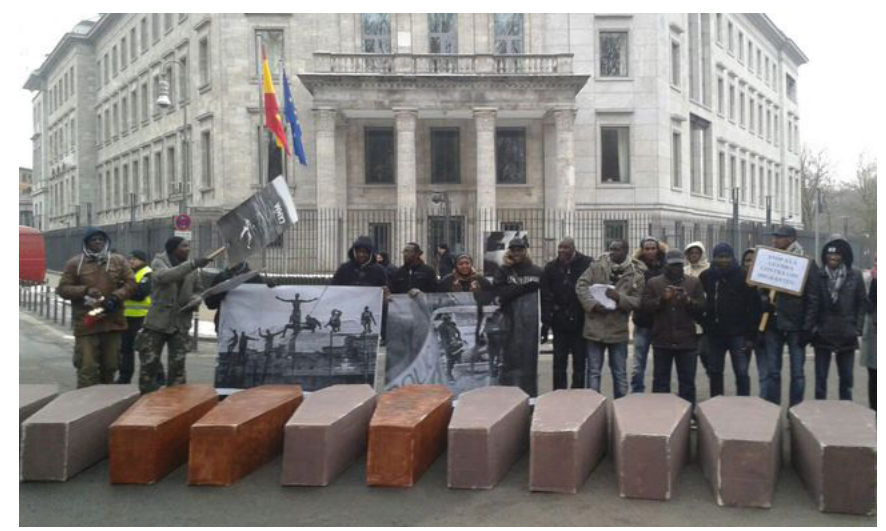

Imagen 8: Ahogados en la playa de Tarajal

Fuente: Recuerdan a las víctimas en la Embajada española en Berlín, Sergi Cámara (2015) 


\section{A MODO DE GONCLUSIONES}

Para construir este apartado se vuelve al principio del estudio, que accede a una de las cuestiones que se ocupa la fenomenología y que sirvió de cimiento para la elección de las fotografías. ¿Cuál es el lugar del sujeto en el mundo? Además, de constituirse en una pregunta compleja, la respuesta irrumpe en el campo de la incertidumbre. Sin embargo, es necesario adentrarse en esta complejidad para intentar contestar a los objetivos que marcaron el camino del artículo.

- En primer lugar, en el discurso silenciado de las imágenes, lo primero que ha emergido es una línea argumental tenue y contradictoria que da a entender que el mundo no es para todos. La exposición de «dos mundos» como metáfora de la dicotomía es lo que ha dibujado la historia en los significados de separación entre las personas «de aquí», con las personas «de allá».

Los resultados ponen de manifiesto que las nuevas dicotomías van ocupando su lugar, donde nuevos conceptos geográficos no impiden la coexistencia de uno de aquí y otro de allá. Deleuze y Guatarri (1993) han escrito que el sujeto «está desterritorializado». ¿Querían decir que el sujeto no tiene lugar ninguno o, dicho de otro modo, que es errante? Si existe la destitución de la geografía como espacio, ¿en qué punto es restituido como espacio simbólico? Mucho más allá del poder y de la dinámica de la exclusión del otro, fue posible visualizar y constatar que existe una acogida de humanización hacia los que sufren el abandono y el cierre de las oportunidades por una política perversa y contradictoria, en el demagógico discurso de atender a los derechos fundamentales de los individuos.

- En segundo lugar, la situación de las personas que se arriesgan en el mar en busca de la supervivencia revela indicadores esenciales: la pobreza está avanzando desenfrenadamente en los países con conflictos internos, cambios climáticos y usurpación de las riquezas desde el periodo de explotación por los países ricos; las guerras provocadas por ideologías hegemónicas de «limpieza étnica», del totalitarismo de gobiernos y el fundamentalismo religioso del grupo radical autodenominado Estado Islámico, que impone el terror por sus brutales asesinatos. Son un resumen de los motivos por los cuales las personas ponen sus vidas en peligro, como un juego de vida o de muerte; no hay otra alternativa y no existen leyes que les protejan contra el hambre y contra las guerras de toda naturaleza. Es un lugar de no pertenencia y discriminación jurídica y social que les impide estar en su patria y en cualquier otro lugar en el mundo.

Es un escenario caótico y de desesperación para el cual la UE rescribe leyes y acuerdos para gestionar la crisis migratoria, pero en realidad frente a cada "problema» reinventa una «misma solución», que es la de frenar la inmigración y expulsar a los inmigrantes «ilegales». Según el propio Director Ejecutivo Adjunto de Frontex considera que «la solución a la inmigración no pasa por el control fronterizo», afirmando que «si alguien lo cree, se equivoca» (El Diario, 30-04-2015). Es decir, 
la política migratoria de control no es la solución para el drama humanitario que se extiende más allá de la burocracia y de la inversión de miles de millones para impedir y expulsar a los que intentan cruzar la línea de la fortaleza de los países ricos.

- En tercer lugar, el imaginario cultural instituido revela que la defensa contra el otro implica una mayor exclusión por temor a la diferencia y a un menor reparto de los beneficios sociales para los no-inmigrantes. No tener esto en cuenta es una conducta que induce a repetir lo que afirmó Freud (1976 [1919]), «el malo es aquel que viene de fuera». Eliminar a los inmigrantes de la ecuación aplaca simbólicamente los sentimientos de miedo y aversión, y solo replica la falacia de que unos son mejores que otros. Son actitudes que han sido una tendencia histórica que alimentan el imaginario colectivo del racismo y de la xenofobia dibujando un (no)lugar de los sujetos en el mundo, que se repite en la historia, cuyos registros fotografiados revelan los escenarios de miedo y exclusión.

- En cuarto lugar, las acciones de la sociedad civil en alta mar, en el contexto fotografiado, han sido realizadas por ONG que buscan salvar vidas, mientras los que registran las imágenes hacen de la información una denuncia frente a las severas políticas migratorias que empujan a las personas a la vía de la clandestinidad o, como dice el propio fotógrafo de la Imagen 1, el griego Messinis, en la isla de Lesbos: «esta es la isla donde la fotografía se convierte en un documento que denuncia la desigualdad social a varias escalas», (El Comercio, 11-09-2016). Son las incoherencias que apuntan para la perversa diferencia de derechos, donde el sujeto de la migración se convierte en un (infr) actor de la ley en busca de la propia sobrevivencia.

Una sociedad con semejante desigualdad social y con la burocracia petrificada (Marx, 1971[1857-1858]) traiciona los sentimientos, encubriendo el rechazo hacia el diferente en sus entramados juegos políticos. Este alcance desde la fenomenología de "estar en el mundo", es mutilado por el poder dominante y la globalización que no contiene sustratos optimistas de los derechos de los hombres, sometidos a un poder burocrático estatal que impide el ejercicio de la libertad. ¿Es lo que señala la idea de desterritorialización como un (no)lugar ya instituido? ¿Hay otra opción para el dilema cuyo destino es migrar hacia la muerte o volver para morir? Qué se puede encontrar aún más delante de la complejidad del interrogante «¿Cuál es el lugar del sujeto en el mundo?».

Independiente de las corrientes antiinmigración, quizás aún hay esperanza, desde el punto de vista de las manos solidarias, reforzada por las palabras del director de la ONG OPEN ARMS Óscar Camps: «Todas esas vidas que rescatamos en el Mediterráneo no son números, son personas con una historia y una voz». ¿Puede ser la mirada para una imagen de un nuevo orden mundial? De un solo mundo que en el estemos todos, con derecho a ser el sujeto de la propia historia. 


\section{BIBLIOGRAFIA}

ACNUR (2017). Desplazamientos forzados alcanza un récord. [En línea]: http://www. acnur.org/recursos/estadisticas/

Acuerdo entre la Unión Europea y Turquía (2016). La crisis migratoria. [En línea]: http:// publications.europa.eu/webpub/com/factsheets/migration-crisis/es/.

Agenda Europea de Migración (2015). [En línea]: https://ec.europa.eu/home-affairs/ sites/homeaffairs/files/what-we-do/policies/european-agenda migration/ backgroundinformation/docs/communication_on the european_agenda_on migration es.pdf.

Ananou, Ouasim y Jiménez Bautista, Francisco (2016). La movilidad transfronteriza: el caso de Melilla-Nador. Revista de Humanidades, nº 28, mayo-agosto, pp. 169-196.

Arango, Joaquín (2017). A través del Mediterráneo: tragedia de los refugiados y crisis de la UE. Anuario CIDOB de la Inmigración, 2015-2016, pp. 1-30.

Augé, Marc (1993). Los no lugares: Espacios del anonimato. Barcelona: Gedisa.

BancoMundial(2017).InformeAnnual2017.[Enlínea]:https://openknowledge.worldbank. org/bitstream/handle/10986/27986/211119SP.pdf?sequence $=11$ \&isAllowed=y

Bauman, Zygmunt (2016). Extraños llamando a la puerta. Buenos Aires: Paidós.

Barthes, Roland (1980). La cámara lúcida. Buenos Aires: Paidós

Bauluz, Javier (2015). Fotografia en la playa de Tarifa, Cádiz-2000. [En línea]: http:// periodismohumano.com/migracion/15-anos-despues-europa-sigue-bajo-lasombrilla.html

Castells, Manuel (2009). Comunicación y poder. Madrid: Alianza Editorial.

Castilla-Vázquez, Carmen (2017). Mujeres en transición: la inmigración femenina africana en España. Migraciones Internacionales, vol. 9, n. 33, pp. 143-171. DOI: http://dx.doi.org/10.17428/rmi.v9i33.290

Cavero, Teresa (2012). Crisis, desigualdad y pobreza. Aprendizajes desde el mundo desarrollado ante los recortes sociales en España. Intermon-Oxfam España. [En línea]: http://www.oxfamintermon.org/sites/default/files/documentos/files/ Informe IO Crisis desigualdad y pobreza 300113.pdf

Cea D’Ancona, Ma Ángeles y Valles Martínez, Miguel S. (2015). Evolución del racismo, la xenofobia y otras formas conexas de intolerancia en España. Madrid: Ministerio de Empleo y Seguridad Social.

Chakour, Toumader y Portillo Fernández, Jesús (2018). La interpretación inferencial y los espacios mentales en el discurso mediático sobre inmigración en España. Revista de Humanidades, n. 33, pp. 63-86. DOI: https://doi.org/10.5944/rdh.33.2018.18504

Deleuze, Gilles e Guattari, Félix (1993). Mil Platôs: capitalismo e esquizofrenia. Vol. 2. Rio de Janeiro: Ed. 34. 
El fotoperiodismo dentro del escenario migratorio... - L.M. Lehnen y otros

Directiva de Retorno (2008). [En línea]: https://eur-lex.europa.eu/legal-content/PT/ TXT/?uri=CELEX\%3A32008L0115

Eco, Umberto (1988). Tratado de Semiótica General. Barcelona: Lumen.

Franquet dos Santos, Miguel; Real Rodríguez, Elena y Beriain Bañares, Ana (2015). La representación mediática de la inmigración en cuatro diarios españoles. Opción: Revista de Ciencias Humanas y Sociales, №. Extra 1, pp. 283-303

Freud, Sigmund (1976, [1919]). In Obras Completas. Vol. XVIII. Buenos Aires: Amorrortu Editores.

Gómez Cortecero, Flor et al. (2017) El fotoperiodismo y su propaganda, el caso de Chiapas. Revista de Cultura de Paz, enero-diciembre, Vol. 1, pp. 85-108.

Jiménez Bautista, Francisco (1997). Juventud y racismo. Actitudes y comportamientos en Granada. Granada: Instituto Municipal de Formación y Empleo, Ayuntamiento de Granada.

Jiménez Bautista, Francisco (2006). La inmigración marroquí en Granada: su imagen y percepción por los jóvenes granadinos. Estudios Geográficos, n² 261, Volumen LXVII, julio-diciembre, pp. 549-578.

Jiménez Bautista, Francisco (2009). Migration in Spain: Andalusia and Granada. International Research. Society, Politics, Economics, no 1, Kazastán, pp. 94-107.

Joffé, George (2011). A Primavera Árabe no Norte de África: origens e perspectivas de futuro. Relações Internacionais $(R: I), \mathrm{n}^{\circ} .30, \mathrm{pp} .85-116$. [En línea]: http://www. scielo.mec.pt/scielo.php?script=sci arttext\&pid=S1645-91992011000200006\&ln $\mathrm{g}=\mathrm{pt} \&$ tlng $=\mathrm{es}$

Kristeva, Julia (1978). Semiótica. Madrid: Fundamentos.

Lacan, Jacques (1970). El reverso del psicoanálisis. Buenos Aires: Paidós.

Martínez, Esperanza y Acosta, Alberto (2017). Los Derechos de la Naturaleza como puerta de entrada a otro mundo posible. Revista Direito e Práxis, Vol. 8(4), pp. 2927-2961. Doi: 10.1590/2179-8966/2017/31220

Martínez Lirola, María y Jiménez Bautista, Francisco (2015). La realidad de las mujeres inmigrantes en las prisiones españolas a través de su discurso: ejemplos de violencia, marginación y reinserción frustrada. Nuevas tendencias en Antropología, $\mathrm{n}^{\mathrm{o}}$ 6, pp. $1-20$.

Maulik, Monami (2017). La Voz de los Migrantes. [En línea]: www.iom.int/entenderlasvulnerabilidades-de-los-migrantes-un-enfoque-basado-en-soluciones

Marx, Karl (1971[1857-1858]). Elementos fundamentales para la crítica de la economía política. Buenos Aires: Siglo XXI.

Medina, Chema (2016). Los refugiados no solo tienen hambre. Asuntos Sociales-Mundo. [En línea]: http://www.democresia.es/asuntos-sociales/refugiados-no-solo-tienenhambre 
Merleau-Ponty, Maurice (1971[1952]). Fenomenologia da percepção. Rio de Janeiro: Freitas Bastos.

Mira Pastor, Enric (2008). Fotografía documental y representación de la inmigración. En Martínez Lirola, María (Coord.). Inmigración, discurso y medios de comunicación, Alicante, Instituto Alicantino de Cultura Juan Gil-Albert, pp. 87-112.

OIM (2016). Muerte de migrantes en Mediterráneo. [En línea]: https://www.iom.int/es.

ONU (2017). Conferência Das Nações Unidas Sobre Mudança Climática. [En línea]: https://unric.org/pt/informacao-sobre-a-onu

Oroza Busutil, Rebeca y Puente Márquez, Yoannis (2017). La crisis migratoria en el Mediterráneo y la Unión Europea: principales políticas y medidas antinmigrantes. Novedades en Población, Vol. 13(26), pp. 1-9.

Peña Díaz, Francisco de Asís (2017). La agenda europea de migración: Últimos desarrollos. Revista Electrónica de Estudios Internacionales (REEI), n ${ }^{\circ} .33$, p. 1-10. DOI: $10.17103 /$ reei.33.10

Pérez Espigares, Pablo (2018). Diferencia y exclusión: alergia al otro en el seno de Europa. Utopía y Praxis Latinoamericana, Vol. 23(80), pp. 171-181.

Santana Ramos, Emilia (2017). La globalización que llega ¿la pobreza que se va? Revista Quaestio Iuris, Vol. 10(3), pp. 1847-1875. Doi: 10.12957/rqi.2017.29111

Sassen, Saskia (2015). Expulsiones. Brutalidad y complejidad en la economía global. Buenos Aires-Madrid, Katz Ediciones.

Sontag, Susan (2006). Sobre la fotografia. Buenos Aires: Alfaguara.

Van Dijk, Teun (2006). Discurso y manipulación: Discusión teórica y algunas aplicaciones. Revista signos, Vol. 39(60), pp. 49-74. DOI: https://dx.doi.org/10.4067/S071809342006000100003

Vargas Martín, Jairo (2015). Europa levanta siete vallas contra el mayor éxodo humano desde la II Guerra Mundial. Revista Kavilando, Vol. 7(2), pp. 187-191. 
